\title{
Mechanical Properties of Corn Husk Flour/PP Bio-composites
}

\author{
Dani. Jagadeesh*, P. Sudhakara*, D.W. Lee*, H.S. Kim*, B.S. Kim**, J. I. Song*广
}

\begin{abstract}
The focus in the present work is to study the agro-waste corn husk bio-filler as reinforcement for polypropylene. These materials have been created by extrusion and injection molding. The effect of filler content by $10,20,30$ and $40 \mathrm{wt}$. \% and mesh sizes of 50 100, 100 and 300 on the mechanical properties was studied. For the un-notched specimens, the results of flexural strength showed a declining trend with increase the filler loading and the results of impact strength showed an increasing trend with increase the mesh size. In contrast, enhanced flexural modulus was observed with increasing filler loading and size.
\end{abstract}

Key Words: agro-waste fillers, mechanical properties, particle size, bio composites, biodegradable polymer

\section{INTRODUCTION}

Agricultural products and its byproducts are profuse and inexpensive sources for the biomass production. Recently, much attention has been paid to utilize forest and agricultural renewable residues as raw material for various industrial applications. These bio-wastes and renewable resources of biomass like cereal straw, corn stalk, flax straw, corn cob, rice husk, represents potentially valuable sources due to their low cost, environmental friendly and sustainable nature [1-5] and it is expected to reduce the dependence on nonrenewable resources and to improve the crisis of energy derived from nonrenewable resources [6,7].

The biomass contains significantly three different polymer entities as cellulose, hemicelluloses and lignin. The use of all the three polymeric components has been discussed since several decades [8]. The various types of ligno cellulose fibers with different amounts of lignin, cellulose and hemi-cellulose, are rendering different adhesion and mechanical properties to the composites. Fibers containing higher lignin content tend to show improved compatibility towards non-polar polymers, since lignin is the most non-polar constituent of the fiber. Fiber properties may be altered due to the micro fibril angle and constituent's concentration.

Natural fiber/PP composites have been used in automotive applications and recently they have been investigated for using in construction, such as building profiles, decking, railing products, etc. Different filler materials have been studied for making poly-propylene composites. These materials include wood, kenaf and sage fibers [9], saw dust [10], flax [11], hemp strand [12], green coconut fiber [13], and organo-montmorillonite [12]. The research group of Korean Institute of Materials Science has published their study dealing with PP-rice husk composites [14].

Corn husk (or hull) in botany is the outer shell or coating of a seed. It often refers to the leafy outer covering of an ear of maize (corn) as it grows on the plant. Corn husk flour is a natural renewable resource that is biodegradable. Corn grows in a great amount around the world $[15,16]$. Besides food and animal feeding applications, a part of corn kernel is also used as a biodegradable matrix [17] or a raw material for producing alcohol (bio-fuel) [18].

\section{MATERIALS AND METHODS}

\subsection{Materials}

A thermoplastic polymer, polypropylene (PP) was supplied by LG Chem. Ltd., Korea, in the form of pellets (Melt Flow Index-g/ $\left.10 \mathrm{~min}\left(1900^{\circ} \mathrm{C} / 2.16 \mathrm{~K}\right)\right)$. Table 1 shows the mechanical properties of PP. In the present study, ligno-cellulosic

접수: 2013년 5월 10일, 수정: 2013년 8월 16일, 게재승인: 2013년 8월 26일

*Department of Mechanical Engineering, Changwon National University, Korea

* Department of Mechanical Engineering, Changwon National University, Korea, Corresponding author (E-mail: jisong@changwon.ac.kr)

${ }^{* *}$ Composites Materials Group, Korea Institute of Materials Science, Korea 
Table 1. Mechanical properties of pure PP

\begin{tabular}{c|c|c}
\hline Flexural Strength & Flexural Modulus & Impact Strength \\
\hline $74 \mathrm{MPa}$ & $3.1 \mathrm{GPa}$ & $26.7 \mathrm{~kJ} / \mathrm{m}$ \\
\hline
\end{tabular}

Table 2. Chemical constituent of the ligno-cellulosic fillers (Values are percentage by weight)

\begin{tabular}{c|c|c|c|c}
\hline & Holo-cellulose & Lignin & Ash & Others \\
\hline CHF & 42.31 & 12.58 & 4.16 & 40.95 \\
\hline RHF & 59.90 & 20.60 & 13.20 & 6.50 \\
\hline WF & 62.50 & 26.20 & 0.40 & 10.90 \\
\hline
\end{tabular}

${ }^{*} \mathrm{CHF}$ and RHF from Ref. [14] and [15].

based corn husk flour (CHF) with different mesh sizes (50100, 100, 300 meshes) were supplied by Corn Products Korea, Inc. Rice husk flour (RHF) and wood flour (WF) both of 100 mesh were supplied by Saron Filler Co., Korea. The chemical composition of the fillers is shown in Table 2 [19]. The naturally occurring agricultural crop residue $\mathrm{CHF}$ was dried in an oven at $100^{\circ} \mathrm{C}$ for 24 hours and then stored in sealed polyethylene bags prior to compounding.

\subsection{Compounding}

The process of mixing PP with husk powder was performed using twin-screw extruder following three-step processes, which are melt blending, extrusion, and pelletizing. Compounding was performed at $190^{\circ} \mathrm{C}$ for $10 \mathrm{~min}$ at a screw speed of $100 \mathrm{rpm}$. The dried pellets were stored in sealed polyethylene bags to avoid moisture infiltration. These CHF/PP mixed pellet were prepared with a stoichiometric ratio of $\mathrm{CHF}$ to PP as 10/90, 20/80, 30/70 and 40/60 wt. \%. The flexural and impact test specimens were prepared at $195^{\circ} \mathrm{C}$ using an injection molding at an injection pressure of 1200 psi and device pressure of 1500 psi. The test specimens were conditioned at $23 \pm 20^{\circ} \mathrm{C}$ and a relative humidity of $50 \pm 5 \%$ for $40 \mathrm{~h}$ as per the ASTM D 618-99 standard prior to testing.

\subsection{Mechanical Testing}

Three points bending test (ASTM D 790-10) was conducted to calculate the flexural property by using Universal Testing Machine (R\&B Co., Korea) at a crosshead speed of $5 \mathrm{~mm} / \mathrm{min}$. Izod impact tests were conducted according to ASTM D 25697 at room temperature. Each obtained value represented the average of five samples.

\section{RESULTS AND DISCUSSIONS}

Incorporation of filler to a polymer matrix may increase or decrease the flexural strength and impact strength of the resulting composite. The fiber type fillers normally improve the flexural strength and impact strength, as the fibers are able to support stresses transferred from the polymer. For irreg-

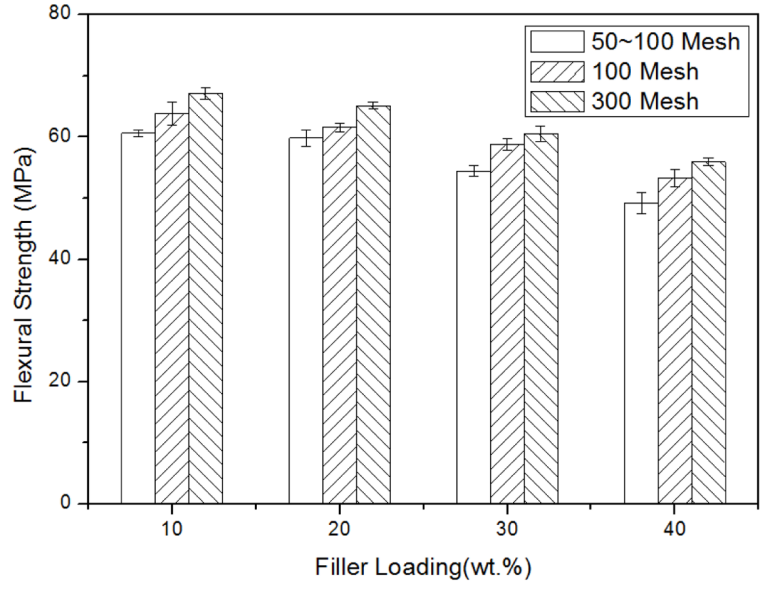

(a) Effect of filler loading

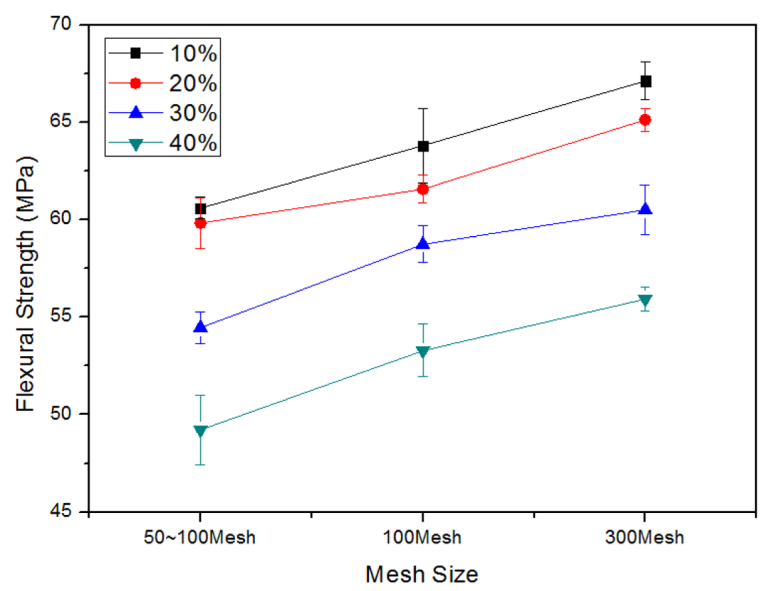

(b) Different mesh sizes

Fig. 1. Flexural strength of the CHF/PP Composites.

ularly shaped fillers, the strength of the composites decreases due to the inability of the filler to support stresses transferred from the polymer matrix.

Fig. 1 shows the flexural strength of CHF/PP composites with different mesh and the content of the flour. From Fig. 1, flexural strength decreased with filler loading and increased with mesh size. However, CHF filled composites showed superior flexural modulus as shown in Fig. 2(a), this higher value may be due to the addition of stiffer material ( $\mathrm{CHF}$ ) into the PP matrix. The results revealed that, the composites developed in the present study showed good bending resistance (tensile and compressive deformations). This further indicates that the interface strength between CHF and PP plays key role in the case of both tensile and compressive deformation. Flexural strength and modulus Fig. 1(b) and Fig. 2(b) development also demonstrates that particle size has greater influence at higher filler load (40 wt. \%), reached a maximum values with a mesh size of 300 which indicate that a greater aspect ratio of the CHF filler that enhances the stiffness of the composites.

The impact strength of CHF composites are shown in Fig. 3(a). From Fig. 3(a), it was observed that the impact strength 


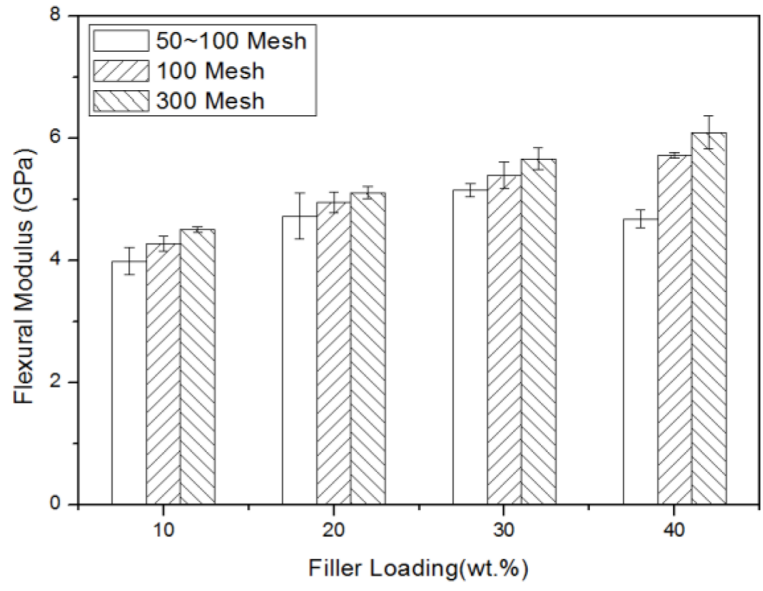

(a) Effect of filler loading

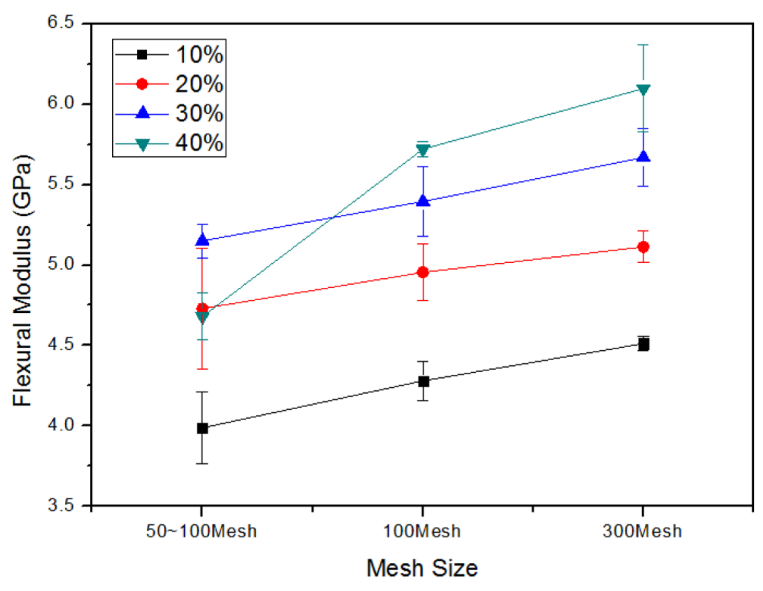

(b) Different mesh sizes

Fig. 2. Flexural modulus of the CHF/PP Composites.

of $\mathrm{CHF} / \mathrm{PP}$ composites is lower than that of the pure PP matrix. This may be expected because the presence of $\mathrm{CHF}$ in PP matrix provides points of stress concentration leading to crack initiation and potential composite failure. During the impact test, cracks travel through the polymer as well as along the weaker interfacial regions. The latter cannot resist crack propagation as effectively as the polymer region, hence reducing the impact strength. Incorporation of fillers is also a considerable reason to inhibit the mobility of polymer, thereby lowering the ability of the system to absorb energy during fracture propagation. Another reason for decrease in impact strength might be due to the stiffening of polymer chains which may be resulted due to the bonding between the $\mathrm{CHF}$ and PP matrix. Moreover, CHF content also increases the probability of cellulosic fiber agglomeration that creates regions of stress concentration that require less energy to elongate the crack propagation. On the other hand, poor impact strength may also be partly attributed to the thermal degradation of fibers due to high shear forces in the kneading section of the twin-screw extruder during compounding. Fig. 3(b) shows that at maximum filler loading, the impact strength

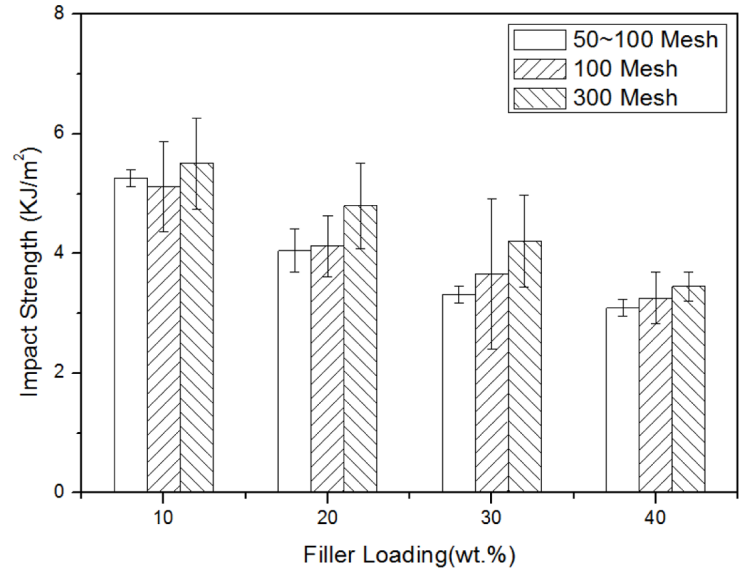

(a) Effect of filler loading

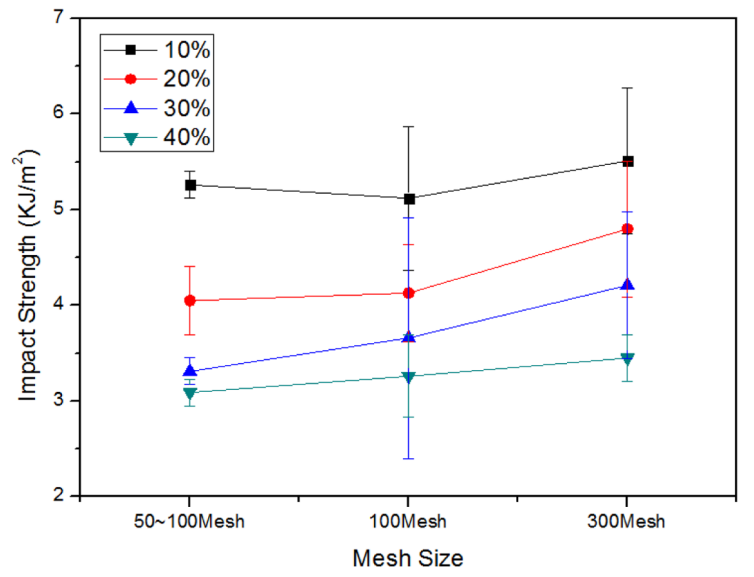

(b) Different mesh sizes

Fig. 3. Impact strength of the CHF/PP Composites.

of the 300 mesh size filler composite is considerably higher than that of the 50 100 composite. Overall, as previously observed in the modulus and tensile properties, the composites filled with larger sized fillers show superior impact property to those with smaller fillers. This observation that the coarse particle filled composites give better performance than fine particles provides a better absorption and dissipation of the impact energy than smaller particles.

\subsection{Water Absorption (24-hr)}

Fig. 4(a) summarizes the maximum water absorption and water diffusion coefficients of the various composites. Generally, the lower filler content and the smaller particle size, have the lower water diffusion coefficients. Due to the high hydrophilic character of the bio-fillers, water absorption is a severe handicap for some applications of natural fiber polymer composites. The results of water absorption showed an increasing trend with increase the filler loading, as well as increase the particle mesh size. In cases of the composites containing 10, 20, and $30 \mathrm{wt}$ \% CHF, the results of water absorption indicated that the presence of voids and spaces plays an 


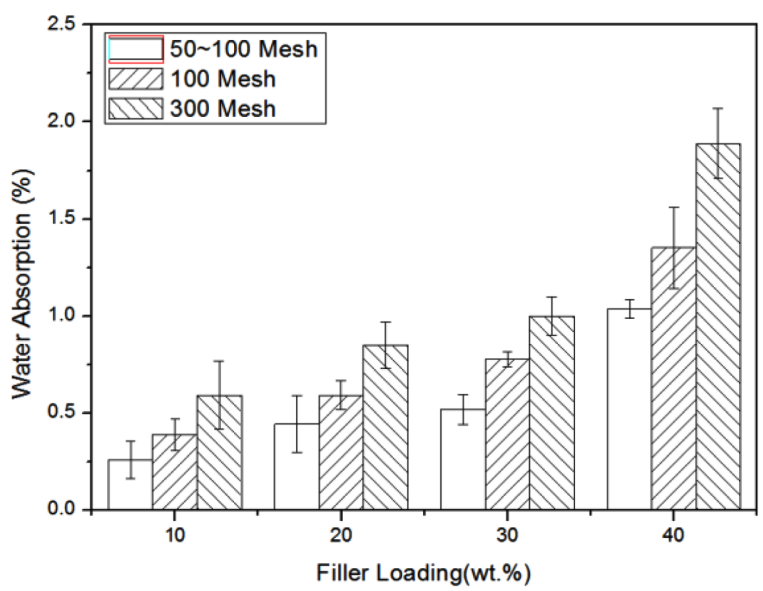

(a) Effect of filler loading

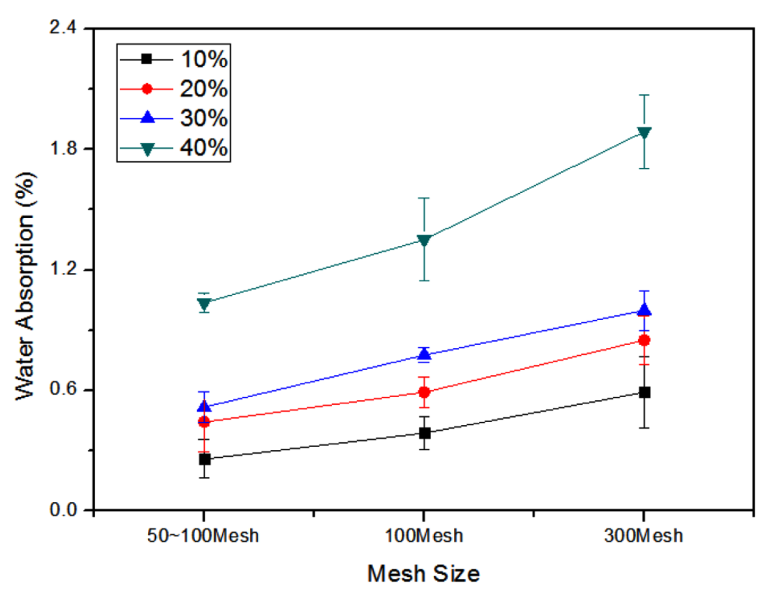

(b) Different mesh sizes

Fig. 4. Water absorption of the CHF/PP Composites.

important role in the degree of water absorption despite of the different hydrophilic compositions. However, for the composites containing $40 \mathrm{wt}$ \% CHF showed the expected behavior of higher level of water absorption attained by the composite with the highest concentration of the hydrophilic filler. This suggests that the water penetration into the filler voids can be more important mechanism of water up taking as the $\mathrm{CHF}$ level increased in composites.

The effect of particle size on water uptake is shown in Fig 4(b). When increase the particle mesh/loading, the water absorption increases. Thus, the effect of fiber length on water uptake is dependent on fiber content. At lower contents, the larger the particle size, the higher the water absorption, which is in good agreement with previous reports [24,25]. This can be explained in two ways: (i) larger particles leads to greater hydrophilic exposed surfaces; and (ii) poor adhesion between $\mathrm{CHF}$ particles and the polymer matrix generates void spaces.

Particle size strongly affects water absorption. As seen in Fig 4 , the smaller the particle size, the higher the water absorption. At $40 \%$ fiber content, composites containing 300-mesh particle size corn husk exhibit the highest water absorption.
Table 3. Mechanical properties of WF/PP, RHF/PP and CHF/PP composites (100 mesh size, 30\%)

\begin{tabular}{c|c|c|c|c}
\hline Materials & $\begin{array}{c}\text { Tensile } \\
\text { Strength } \\
(\mathrm{MPa})\end{array}$ & $\begin{array}{c}\text { Flexural } \\
\text { Strength } \\
(\mathrm{MPa})\end{array}$ & $\begin{array}{c}\text { Flexural } \\
\text { Modulus } \\
(\mathrm{GPa})\end{array}$ & $\begin{array}{c}\text { Impact } \\
\text { Strength } \\
\left(\mathrm{KJ} \mathrm{m}^{-1}\right)\end{array}$ \\
\hline $\mathrm{WF} / \mathrm{PP}$ & $27.98+2.80$ & $65.03+4.43$ & $7.58+1.07$ & $15.68+2.38$ \\
\hline $\mathrm{RHF} / \mathrm{PP}$ & $25.6+1.36$ & $60.55+2.43$ & $6.17+2.08$ & $15.85+1.79$ \\
\hline $\mathrm{CHF} / \mathrm{PP}$ & $22.28+2.29$ & $53.29+4.13$ & $5.39+3.41$ & $15.35+3.94$ \\
\hline
\end{tabular}

\subsection{Comparison of WF/PP, RHF/PP and CHF/PP Com- posites}

Resulted flexural strength, flexural modulus and impact strength of PP composite samples are presented in Table 3. As shown in Table 3, flexural strength, flexural modulus and impact strength of the CHF (30 wt. \%, 100 mesh) filled bio composites was lower than those of WF and RHF filled (30 wt. \%, 100 mesh) bio-composites. Adversely, flexural strength was decreased by the addition of WF, RHF and CHF. This decrement may be attributed to the incapability of the filler, irregular shape, to support stress transfer from the polymer matrix and poor interfacial bonding generates partially spaces between fiber and polymer matrix, as a result which generates weak structure. Similar results were also reported in the literature [26,27]. Another strong reason for lowering the mechanical properties of $\mathrm{CHF} / \mathrm{PP}$ composites is the cellulose content in the filler 40 . The CHF has lower cellulose content (42\%) compare to Wood flour (62.5\%) and RHF (60\%). Hence, mechanical properties of $\mathrm{CHF} / \mathrm{PP}$ composites are lower than those of WF/PP and RHF/PP composites. Furthermore, the higher amount of silica in the CHF, which is partially responsible for insufficient adhesion between the $\mathrm{CHF}$ and the PP matrix, is likely to be an essential factor in determining the properties of $\mathrm{CHF} / \mathrm{PP}$ composites. The impact strength of PP bio-composites filled with WF, RHF and CHF (100 mesh size and 30\%) are presented in Table 3. The impact strength of these composites was not statistically significant. However, for specific applications, the impact strength can be improved by using impact modifiers or by using natural fibers having higher micro fibril angle.

\section{CONCLUSION}

Based on the above results following conclusions can be drawn.

1. The flexural and impact strength of the CHF/PP composites significantly decreased with increasing filler content. However, CHF/PP composites retained an acceptable level of strength.

2. The tensile, flexural and impact properties of bio-composites increased with decreasing particle size. The lower mesh size of CHF offers larger specific surface area in the bio composites than those of larger $\mathrm{CHF}$ mesh size at the same weight 
fraction.

3. The mechanical properties of CHF/PP (30 wt. \%, 100 mesh) composites was lower than those of WF and RHF filled (30 wt. \%, 100 mesh) bio-composites due to the lower cellulose content of CHF (42\%) filled PP composites

\section{ACKNOWLEDGEMENT}

This work was supported by the National Research Foundation of Korea (NFR) grant funded by the Korea government (MEST) (No.2012-0009455). This research was supported by Basic Science Research Program though the National Research Foundation of Korea (NRF) funded by the Ministry of Education, Science and Technology (No.2012-0008302) and Brain Korea (BK21) Projects Corps of the second phase.

\section{REFERENCES}

1. Nourbakhsh, A., Ashori, A., and Biores, "Wood Plastic Composites from Agro-waste Materials: Analysis of Mechanical Properties," Bioresource Technology, Vol. 101, 2010, pp. 25252528.

2. Kim, H.S., Yang, H.S., and Kim, H.J., "Biodegradability and Mechanical Properties of Agro-flour-filled Polybutylene Succinate Biocomposites," Journal of Applied Polymer Science, Vol. 97, 2005, pp. 1513-1521.

3. Peng, F., Bian, J., Ren, J.L., Peng, P., Xu, F., and Sun, R.-C., "Bioconversion of Sugarcane Biomass into Ethanol : An Overview about Composition, Pretreatment Methods, Detoxification of Hydrolysates, Enzymatic Saccharification, and Ethanol Fermentation," Biomass and Bioenergy, Vol. 39, 2012, pp. 20-32.

4. Kim, H.S., and Kim, H.J., "Colorless Polyimide Nanocomposite Films: Thermomechanical Properties, Morphology, and Optical Transparency," Journal of Applied Polymer Science, Vol. 107, 2008, pp. 109-117.

5. Gahleitner, M., and Kretzschmar, B., "Morphology and Mechanical Properties of Polypropylene/polyamide 6 Nanocomposites Prepared by a Two-step Melt-compounding Process," Journal of Applied Polymer Science, Vol. 100, 2006, pp. 283291.

6. Najafi, S.K., Hamidinia, E., and Tajvidi, M., "Mechanical Properties of Composites from Sawdust and Recycled Plastics," Journal of Applied Polymer Science, Vol. 100, 2006, pp. 3641-3645.

7. Moran, J., Alvarex, V., Petrucci, R., Kenny, J., and Vazquez, A., "Mechanical Properties of Polypropylene Composites Based on Natural Fibers Subjected to Multiple Extrusion Cycles", Journal of Applied Polymer Science, Vol. 103, 2007, pp. 228-237.

8. Mutje, P., Vallejos, M.E., Girones, J., and Vilaseca, F., "Effect of Maleated Polypropylene as Coupling Agent for Polypropylene Composites Reinforced with Hemp Strands," Journal of Applied Polymer Science, Vol. 102, 2006, pp. 833-840.

9. Leblanc, J.L., Furtado, C.R.G., and Leite, M.C.A.M., "Investigating Polypropylene-Green Coconut Fiber Composites in the Molten and Solid States Through Various Techniques," Journal of Applied Polymer Science, Vol. 102, 2006, pp. 1922-1936.

10. Yi, W.W., Fei, Z.X., Guan, W.G., and Feng, C.J., "Preparation and Properties of Polypropylene Filled with Organo-montmorillonite Nanocomposites," Journal of Applied Polymer Science, Vol. 100, 2006, pp. 2875-2880.
11. Genevive C. Onuegbu, Isaac Ogbennaya Igwe, "The Effects of Filler Contents and Particle Sizes on the Mechanical and EndUse Properties of Snail Shell Powder Filled Polypropylene," Materials Sciences and Application, Vol. 2, 2011, 811-817

12. Aithani D, Mohanty, "Injection Molded Novel Green Materials from the Byproduct of Corn-based Ethanol Industry," A Society of Plas Engin Boston, 2005, pp. 6147-6152.

13. USDA National Agricultural Statistics Service. Available at http://www.nass.usda.gov/data_and_statistics/quick_stats/index. asp\#top, accessed 08/04/2007.

14. Marques, A.P., Reis, R.L., and Hunt, J.A., "The Biocompatibility of Novel Starch-based Polymers and Composites: in vitro Studies," Biomaterials. Vol. 23, 2002, pp. 1471-1478.

15. Beery, K.E., Mosier, N.S., Hendrickson, R., Brewer, M.A., Dien, B.S., and Bothast, R.J., "A 19F Nuclear Magnetic Relaxation Study of Micelle Formation in Aqueous Solutions of Heptafluorobutyric Acid and Sodium Pentadecafluorooctanoate," American Chemical Society, Vol. 46, 2000, pp. 212-219.

16. Mohd, Z., Mohamhed, Y., Mohd, S.S., IsmailL, N., and Riza, W., "Mechanical Properties of Short Random Oil Palm Fibre Reinforced Epoxy composites," Sains Malaysiana, Vol. 39, 2010, pp. 87-92.

17. Kord, B., world, "Crystallization Behavior of Natural FiberReinforced Plastic Nanocomposite," Science Applied Journal, Vol. 13, 2011, pp. 1329-1332.

18. Jilken, L., Malhammar, G., and Selden, R., "The Effect of Mineral Fillers on Impact and Tensile Properties of Polypropylene," Polymer Testing, Vol. 10, 1991, pp. 329-344.

19. Fuad, M.Y.A., Ismail, Z., Ishak, Z.A., and Omar, A.K., "Application of Rice Husk Ash as Fillers in Polypropylene: Effect of Titanate, Zirconate and Silane Coupling Agents," European Polymer Journal, Vol. 31, 1995, pp. 885-893.

20. Kim, H.S., Yang, H.S., and Kim, H.J., "Biodegradability and Mechanical Properties of Agro-flour-filled Polybutylene Succinate Biocomposites," Journal of Applied Polymer Science, Vol. 97, 2005, pp. 1513-21.

21. Yang, H.S., Kim, H.J., Park, H.J., Lee, B.J., and Hwang, T.S., "Water Absorption Behavior and Mechanical Properties of Lignocellulosic Filler-polyolefin Bio-composites," Composite Structure, Vol. 72, 2006, pp. 429-437.

22. Kendall, K., "Fracture of Particulate Filled Polymers," British Polymer, Vol. 10, 1977, pp. 35-38.

23. Raj, R.G., Kokta, B.V., Grolaeu, G., and Daneault, C., "Use of Wood Fibers in Thermoplastics. VII. The Effect of Coupling Agents in Polyethylene-wood Fiber Composites," Journal of Applied Polymer Science, Vol. 37, 1989, pp. 1089-1103.

24. Zhaini, M.J., Fuad, M.Y.A., Ismail, Z., Mansor, M.S., and Mustafah, J., "The Effect of Filler Content and Size on the Mechanical Properties of Polypropylene/oil Palm Wood Flour Composites," Polymer Intl. Vol. 40, 1995, pp. 51-55.

25. Bigg, D.M., "Mechanical Properties of Particulate Filled Polymers," Polymer Composites, Vol. 8, 1987, pp. 115-122.

26. Fuad, M.Y.A., Ismail, Z., Ishak, Z.A.M., and Omar, A.K.M., "Effect of Titanate, Zirconate and Silane Coupling Agent," European Polymer Journal, Vol. 31, 1995, pp. 885-892.

27. Fan, Y., Lou, J., and Shinozaki, D.M., "Microstructure Dependent Properties of Polypropylene-clay Nanocomposites," Journal of Applied Polymer Science, Vol. 103, 2007, pp. 204-210.

28. Maiti, S.N., and Singh, K., "Influence of Wood Flour on the Mechanical Properties of Polyethylene," Journal of Applied Polymer Science, Vol. 32, 1985, pp. 4285-4289. 